\title{
Youth Quarter: Success and Failure Factors of a Digital Platform for Youth Care Professionals
}

\author{
Margreet B. Michel-Verkerke \\ Saxion University of Applied Sciences \\ $\underline{\text { m.b.michel@saxion.nl }}$
}

\author{
Somaya Ben Allouch \\ Saxion University of Applied Sciences \\ s.benallouch@saxion.nl
}

\begin{abstract}
The digital platform Youth Quarter is built by youth care organizations with the intention to facilitate youth care professionals to share knowledge. The adoption of Youth Quarter is investigated using the USE IT-adoption-model. Interviews with 27 youth care professionals demonstrated that the main problem they experience is high working pressure. Youth Quarter does not relieve the working pressure nor solves other relevant problems. Youth Quarter is regarded as having little relevance and not meeting users' requirements, because of the little content and low number of users. Youth care professionals prefer to consult colleagues, and professionals they know. To increase the adoption, Youth Quarter should reward users by providing up-to-date relevant information and knowledge, and support efficient and effective working processes. Management should share clear goals for Youth Quarter and encourage the use of Youth Quarter, in order to increase the adoption.
\end{abstract}

\section{Introduction}

Youth care in The Netherlands endured major changes in the last three years. The new Youth Law initiated a transition in responsibilities and budgets for youth care from the national government and health insurance to local authorities. The transition was accompanied by a transformation from professionaland care provider-driven care to area and family focused care, in which supporting clients and families should dominate, instead of treating individual youngsters. The objective of transition and transformation of youth care is to improve efficiency and effectiveness of youth care. Youth care professionals are confronted with a new way of providing care. They need to approach clients in a different way, and the need to collaborate more with other professionals, clients, and family in constantly changing networks.
In the region Twente in The Netherlands a cooperation of youth care organizations anticipated on these changes in youth care law and policy by building the digital platform Youth Quarter in order to facilitate youth care professionals in collaboration and knowledge sharing.

\subsection{What is Youth Quarter?}

The concept on which Youth Quarter is built contains elements of an Intranet, and social media platforms like LinkedIn and Facebook. Users are required to create an account with a profile in which they introduce themselves. Users can join thematic 'circles' (groups), like Divorce, Autism and Abuse. In a circle youth care professionals can consult each other, discuss or share information.

The Home page has several sections, like News, Agenda, Training \& Workshops, Who is Who, and an invitation to submit questions to an e-mail address. Answers will be published at the Home page or in a circle. The structure of Youth Quarter is still developing, dependent on the feedback of users.

This research intends to evaluate the introduction of Youth Quarter.

\subsection{Social networks in organizations}

Organizations can have different objectives when they introduce social networks for professionals. Turban, Bolloju and Liang [1] distinguish six categories:

1. Information dissemination and sharing

2. Communication

3. Collaboration and innovation

4. Training and learning

5. Knowledge management

6. Management activities and problem solving

The primary objectives of Youth Quarter can be categorized as 3. Collaboration and innovation, and 5. Knowledge management. However, Youth Quarter could be applied for the other purposes - except 6 . Management activities - as well.

Whether objectives are achieved, depends on company size, innovation experience, strength of the network. Knowledge institutes and smaller, innovative 
companies with strong network bonds benefit most from social networks, especially in the initial phase of the network [2]. The amount of knowledge exchanged in a network, not only depends on the objectives and participants in the network. Also characteristics of the knowledge itself determine the effort that is taken. When knowledge is difficult, important and external, the effort for knowledge transfer increases [3]. Organizations often refrain from transferring implicit knowledge, because it is hard to transfer, and requires a lot of effort [3]. A simple and inexpensive way of sharing knowledge between organizations, is the creation of virtual teams $[4,5]$. A disadvantage of virtual teams is the lack of incidental encounters between employees in corridors, at the coffee machine and the like [6]. Since the chance to meet a likeminded is large in an incidental encounter, virtual teams and digital social networks should encourage and enable incidental encounters [7].

When an organization has clear goals for the use of knowledge sharing through social networks, and when the organization shares these goals with their employees, these employees are more willing to use social networks, provided the employees already have interrelationships [8].

Investigation of motives of people for using Facebook, reveals that social networks support people in positioning themselves as a member of a group, and enables them to have the feeling of being elsewhere [9]. Other reasons to use Facebook are pleasure and usefulness. Both can only be accomplished when a minimum number of users is achieved. This threshold is more important than complimentarity [10].

In summary it can be stated that sharing knowledge digitally is simple and cheap. Organizations use social networks for several purposes; especially innovative and knowledge producing organizations benefit from social networks. However, incidental encounters must remain possible, and social networks should be used by enough people. Organizations should be clear in their objectives and share these objectives with their employees.

\subsection{Adoption of technology}

The development or implementation of new technology often starts with a requirement analysis. However, intended users often only have a vague idea, what requirements should be met by the technology. Moreover the adoption of technology depends on more factors than meeting the requirements. In this research adoption is defined as: "a decision to make full use of an innovation as the best course of action available"[11]. Several models and theories are developed to predict the adoption of technology, e.g. the Technology Acceptance Model [12, 13], the
Diffusion of Innovations [11], and the Information Systems Success Model [14]. The USE IT-adoptionmodel integrates these models and theories and specifies the determinants for the adoption of technology in healthcare $[15,16]$.

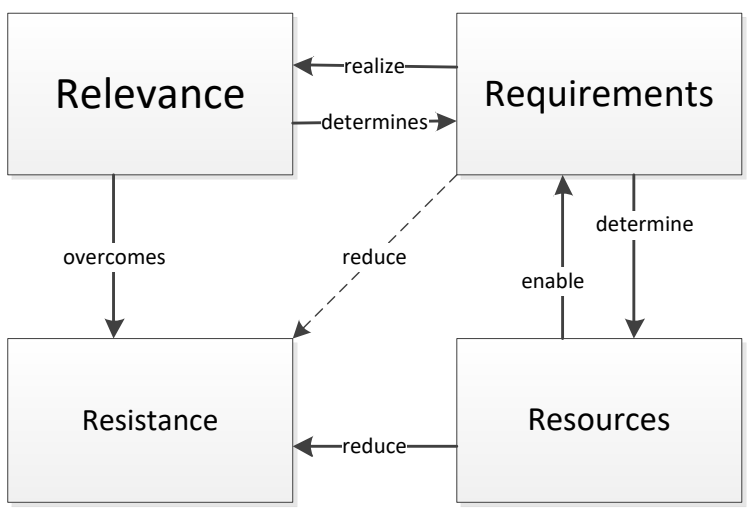

Figure 1. USE IT-adoption-model [15, 16].

The USE IT-adoption-model distinguishes four determinants: relevance, requirements, resources and resistance. All four determinants can be measured at an individual (micro-) and at an organizational (macro-) level. Figure 1 depicts the relations between the determinants in the USE IT-adoption-model. The determinants contain dimensions, which are listed at the micro-level in Table 1.

Table 1. Sub-dimensions on micro-level

\begin{tabular}{|l|l|}
\hline Determinant & Dimension \\
\hline Relevance & Task support \\
\cline { 2 - 2 } & Effective care (quality of care) \\
\cline { 2 - 2 } & Efficient care (reduce workload) \\
\cline { 2 - 2 } & Customer (patient) satisfaction \\
\hline Requirements & Information quality \\
\cline { 2 - 2 } & Accessibility (anywhere, anytime) \\
\cline { 2 - 2 } & Compatibility \\
\cline { 2 - 2 } & Interface satisfaction \\
\cline { 2 - 2 } & Interoperability \\
\hline \multirow{5}{*}{ Resources } & Material: \\
\cline { 2 - 2 } & $\begin{array}{l}\text { Access to infrastructure / technical } \\
\text { resources }\end{array}$ \\
\cline { 2 - 2 } & Immaterial: \\
\cline { 2 - 2 } & Capabilities (physical, cognitive) \\
\cline { 2 - 2 } & Experience / education \\
\hline Resistance & Lack of trust \\
\cline { 2 - 2 } & Low tolerance of change \\
\cline { 2 - 2 } & Negative consequences \\
\hline
\end{tabular}

Micro-relevance is defined as: The degree to which the ICT-system helps to solve the here-and-now problem of the user in his working process and 
provides benefits. Micro-relevance proves to be the dominant determinant in adoption $[15,16]$.

\subsection{Research objective}

The research aims to evaluate the initial phase of Youth Quarter establish success and failure factors for the adoption by youth care professionals of Youth Quarter.

\section{Methods}

Twenty-seven youth care professionals, 23 women and 4 men, were interviewed according to the USE ITadoption-model. About two-third of the respondents had registered to use Youth Quarter, more than half of them being part of the initial approximately 50 users. A convenience sample strategy is used in which is sought for diversity in types of professions and organizations.

Table 2. Interview questions (examples)

\begin{tabular}{|l|l|}
\hline Topic & Question \\
\hline Work process & Could you describe your tasks? \\
& $\begin{array}{l}\text { Do you collaborate with people } \\
\text { inside or outside your organization? } \\
\text { With whom? } \\
\text { How do you feel about the } \\
\text { collaboration? }\end{array}$ \\
\hline Relevance & $\begin{array}{l}\text { What is really important for you, } \\
\text { personally, in doing your tasks? } \\
\text { When are you satisfied at the end of } \\
\text { a working day? }\end{array}$ \\
& $\begin{array}{l}\text { Do you experience bottlenecks? If } \\
\text { so, which? } \\
\text { How could ICT or Youth Quarter } \\
\text { support you in doing your tasks? }\end{array}$ \\
\hline Requirements & $\begin{array}{l}\text { What information do you need to do } \\
\text { your tasks? } \\
\text { Does the information you get, } \\
\text { suffice? } \\
\text { What is your experience in using } \\
\text { Youth Quarter? }\end{array}$ \\
\hline Resources & $\begin{array}{l}\text { Do you have (adequate) access to } \\
\text { technology you need? } \\
\text { Do you feel comfortable using ICT? } \\
\text { Do you have access to Youth } \\
\text { Quarter? }\end{array}$ \\
\hline $\begin{array}{l}\text { How do you feel about changes in } \\
\text { your work? } \\
\text { How do you feel about using ICT or } \\
\text { other technology? } \\
\text { How do you feel about using Youth } \\
\text { Quarter? }\end{array}$ \\
\hline
\end{tabular}

A semi-structured interview-model was used to measure the determinants of the USE IT-adoptionmodel on the individual (micro-)level. Depending on the course of the interview, questions were added, skipped or rephrased. Table 2 gives some examples of interview questions.

The interviews were transcribed and analyzed using a coding scheme based on the determinants of the USE IT-adoption-model. Fragments and statements were coded, labeled and ordered according to the coding scheme.

\section{Results}

The respondents worked in ambulant and institutional care, in social work, psychiatry, mental health care, and foster care, all targeted at children and youngsters. Two-third of the respondents main task was client care, one-third had mainly managerial or organizational tasks.

\subsection{Care process}

The transition and transformation in youth care were accompanied by budget cuts and competition between care organizations. Youth care professionals notice that administrative and support staff is reduced, resulting in a higher workload for caregivers.

Collaboration and consultation between care professionals is still mostly restricted to colleagues with the same profession. Inter-organizational collaboration is awkward because of the (forced) competition. Referring clients to another organization with needed expertise, is experienced as more difficult than before the transition, because of change in legislation and financial rules. Professionals of different organizations collaborate and consult each other when they know each other personally, respect each other's expertise and trust each other. Communication between professionals is by (mobile) telephone, e-mail, and face-to-face meetings.

\subsection{Relevance}

When respondents are asked what is important to them, and what motivates them, the answer is: client care. Supporting the young clients in helping to solve their problems, to learn to deal with their needs and disabilities, and to improve their lives, motivates youth care professionals. Being able to observe progress is the reward youth care professionals seek. Second motivation is good contact with colleagues. Working in a team in which trust, respect, communication, and knowledge sharing is the norm, enables professionals to enjoy their job. 
Although the positive experiences prevail, bottlenecks are also mentioned. A high workload is the dominant bottleneck respondents experience. They blame the transition and related changes, like budget cuts, competition and a central role of municipalities, for this. Other bottlenecks are failing information- and communication technology (ICT), confusing information sources, interrupting communication, and lack of quiet workplaces.

Youth Quarters is hardly used by the respondents. They don't have or don't make time to log on, and feel they don't need Youth Quarter to fulfill their tasks. If they use Youth Quarter it is only to read, information is seldom uploaded. Although the possibility of retrieving and sharing knowledge in Youth Quarter is appreciated, respondents continue to seek information elsewhere. Another relevant use for youth care professionals would be to enlarge their professional network. Some respondents consider Youth Quarter as one of the many information systems, and do not see the added value of it.

\subsection{Requirements}

Youth care professionals communicate a lot. The communication is mostly restricted to the own organization and targeted to finding the optimal place of care or treatment for a client. Client information is retrieved and registered in electronic client records. Professional knowledge is mainly obtained from intranet, colleagues, internet and official guidelines. The information obtained is often shared with colleagues by e-mail, but also in meetings and other ways of communication. Respondents are satisfied about the sharing of information within their organizations. However, sharing information with professionals in other organization is far less, despite the desire to do so. Sharing information with other organizations concerns specific topics, like divorce, sexual abuse and intimidation, and drugs.

According to the respondents Youth Quarter should be easy to use, well organized, and contain expert knowledge about specific topics. Youth Quarter should also facilitate exchange of information about what specialist care is offered where, and actual information about its access and availability. To stimulate the use of Youth Quarter for retrieving expert knowledge, fast answers to posted questions are required. A prerequisite for sharing expert knowledge is trust and confidence. Confidence in the expertise of the professional who shares the knowledge, and trust that some who asks questions is not blamed for being 'ignorant' or damaging the organization's reputation. The e-mail notification of Youth Quarter stimulates respondents to have a look at the offered information.

\subsection{Resources}

Computers and smartphones are widely used by youth care professionals, although some respondents still use paper to make notes and preliminary reports, which need to be entered electronically later. These respondents would like to have a tablet in order to be able to report directly in the electronic record. Another reason for wanting a tablet is to use it for 'videocalling' (like Facetime or Skype), which is implemented in many care organizations.

Although respondents all use ICT to perform their tasks, older respondents doubt whether they have enough skills to use Youth Quarter. When Youth Quarter will be implemented wider, face-to-face training and workshops are preferred.

\subsection{Resistance}

Most respondents expose a positive attitude towards Youth Quarter. They think Youth Quarter can offer a lot of useful information and knowledge. Also the possibility to contact people with the same interests, and expertise is considered useful. However, most respondents keep intending to use Youth Quarter without actually doing it. They prefer personal contact with people they have met before. Youth care is considered to be 'humans' work', technology is often regarded as impersonal.

\section{Discussion}

The digital platform Youth Quarter was initiated in order to facilitate knowledge sharing and collaboration, and to prevent loss of expert knowledge. This research was focused on finding success and failure factors for the adoption of Youth Quarter by youth care professionals.

\subsection{Answer to the research question}

Relevance: The research reveals that youth care professional are driven by the objective to provide high quality care, and improve the clients' situation. Youth Quarter could contribute to realize a high quality of care by providing expert knowledge. However, because Youth Quarter is hardly used, and lacks a sufficient amount of content, task support of Youth Quarter is not experienced by youth care professionals. Youth Quarter so far failed to attract a critical mass of users [10]. The information that is available is appreciated. The main bottleneck respondents experience is a high workload. Youth Quarter does not relieve this. Relevance on the micro-level is low, which explains the low degree of adoption [16].

Requirements: Since Youth Quarter is distributed on the Internet, it is accessible with computer or smartphone. However the interface should be adapted 
to improve the usability on smartphones. Youth Quarter is designed as a stand-alone solution and does not link to the intranets of affiliated organizations. Neither is the use of Youth Quarter integrated in the working process of youth care professionals (compatibility).

Resources: Although some older respondents doubt whether they will be able to learn to use Youth Quarter, youth care professionals do have enough experience and skills in using ICT for work purposes.

Resistance: Youth care professionals prefer to exchange information face-to-face with colleagues. They fear a loss of personal contact when using Youth Quarter [6]. The transition and transformation in youth care stimulates competition between care organizations. This makes employees of these organizations cautious in sharing expertise, but also in sharing questions, because they are uncertain whether they are allowed to share information, and they are afraid of harming their employer. In order to resolve this caution, care organizations need to phrase and share their goals for Youth Quarter with their employees [8].

Table 3. Success and failure factors Youth Quarter

\begin{tabular}{|c|c|c|}
\hline Determinant & Dimension & Success \\
\hline \multirow[t]{4}{*}{ Relevance } & Task support & No \\
\hline & $\begin{array}{l}\text { Effective care (quality of } \\
\text { care) }\end{array}$ & Moderate \\
\hline & $\begin{array}{l}\text { Efficient care (reduce } \\
\text { workload) }\end{array}$ & No \\
\hline & $\begin{array}{l}\text { Customer (patient) } \\
\text { satisfaction }\end{array}$ & No \\
\hline \multirow[t]{5}{*}{ Requirements } & Information quality & Moderate \\
\hline & $\begin{array}{l}\text { Accessibility (anywhere, } \\
\text { anytime) }\end{array}$ & Yes \\
\hline & Compatibility & No \\
\hline & Interface satisfaction & Moderate \\
\hline & Interoperability & No \\
\hline \multirow[t]{5}{*}{ Resources } & Material: & \\
\hline & $\begin{array}{l}\text { Access to infrastructure / } \\
\text { technical resources }\end{array}$ & Yes \\
\hline & Immaterial: & \\
\hline & $\begin{array}{l}\text { Capabilities (physical, } \\
\text { cognitive) }\end{array}$ & Yes \\
\hline & Experience / education & Yes \\
\hline \multirow[t]{3}{*}{ Resistance } & Lack of trust & Moderate \\
\hline & Low tolerance of change & No \\
\hline & Negative consequences & Moderate \\
\hline
\end{tabular}

Table 3 gives an overview of the success and failure factors in relation to the determinants of the USE IT-adoption-model.

\subsection{Quit or continue Youth Quarter?}

The youth care organizations initiated Youth Quarter in order to prevent loss of knowledge and expertise due to the changes in the organization of youth care in the Netherlands. Respondents in this research do not experience this 'brain drain'. It is still too early to decide whether the employers are ahead of their time, or whether they are anticipating a problem that will not occur. However, when the care organizations want Youth Quarter to be adopted by their employees, they need to increase the relevance by integrating Youth Quarter in their organizational communication channels (such as Intranets), and by providing highly relevant up-to-date expert knowledge, and quick responses to questions. The employers also need to advocate use of Youth Quarter by creating shared goals.

\subsection{Strengths and weaknesses}

The respondents represented initial, late and nonusers of Youth Quarter, which guarantees the credibility of the results. Inherent to a qualitative research is the subjective nature of the results. However, since this research was targeted at studying behavior, asking respondents about their ideas and opinions strengthened the authenticity [17].

\section{Conclusion}

Youth care professionals put clients and their families first. Financial cuts, competition, decreased organizational and professional support due to the changes in youth care, make youth care professionals experience an increased workload. Collaboration between organizations decreases, and knowledge exchange and consultation mainly occurs with colleagues and trusted other professionals. Information is retrieved from the organizational Intranet (network). Youth professionals are satisfied about the interprofessional communication, although this is time consuming, and ad hoc communication is often disturbing/interrupting.

The Youth Quarter is hardly used, because of increased workload, many organizational changes and lack of relevant content. Youth Quarter was initiated to prevent loss of expertise in this turbulence. Time will tell whether Youth Quarter came too early or is trying to solve a problem that does not exist.

\section{Acknowledgement}

This research could not have been completed without the support of Ilse Boswinkel, Elly van der Helm and Tamara Loohuis. The authors also like to 
thank Saxion students Thomas Bekkedam, Manon Reinders, Lenneke Scheltema and Kelly Schiff for their contribution to the research.

\section{References}

[1] E. Turban, N. Bolloju and T-P. Liang, "Enterprise Social Networking: Opportunities, Adoption, and Risk Mitigation", Journal of Organizational Computing and Electronic Commerce, 2011, 21, pp. 202-220, doi:10.1080/10919392.2011.590109.

[2] M. Fritsch and M. Kauffeld-Monz, "The Impact of Network Structure on Knowledge Transfer: An Application of Social Network Analysis in the Context of Regional Innovation Networks", Jena Economic Research Papers, 2008-036, http://hdl.handle.net/10419/25722.

[3] J. Kang, M. Rhee and K. H. Kang, "Revisiting Knowledge Trasnfer: Effects of Knowledges Characteristics on Organizational Effort for Knowledge Transfer", Expert Systems with Applications, 37, pp. 8815-8160, doi:10.1016/j.eswa.2010.05.072.

[4] M. Chui, J. Manyika, J. Bughin, R. Dobbs, C. Roxburgh, H. Sarrazin, et al. "The social economy: Unlocking value and productivity through social technologies, McKinsey Globel Institute, 2012, http://mckinsey.com/insights/high_tech_telecoms_internet/th e_social_economy.

[5] J. Linpack and J. Stamps, Virtual Teams, John Wiley \& Sons: Canada, 2000

[6] R.E. Kraut, R.S. Fish, R.W. Root, B.L. Chalfonte and I.S. Oskamp, "Informal Communication in Organization", Readings in Groupware and Computer-Supported Cooperative Work: San Francisco.

[7] W. Vermeulen, "Wordt de wereld plat of is er toekomst voor de stad?", TPE Digitaal, 2014, 8, pp. 84-98, http://www.tpedigitaal.nl/assets/static/10_-1-2014.pdf .

[8] W.S. Chow and L.S. Chan, "Social Network, Social Trust And Shared Goals In Organizational Knowledge Sharing",
Information \& Management, 2008, 45, pp. 458-465, doi: 10.1016/j.im.2008.06.007.

[9] O. Kwon and Y. Wen, "An Emperical Study of the Factors Affecting Social Network Service Use", Computers in Human Behavior, 2009, 26, pp. 254-263, doi:10.1016/j.chb.2009.04.011.

[10] K-Y. Lin and H-P. Lu, "Why People Use Social Networking Sites: An Empirical Study Integrating Network Externalities and Motivation Theory", Computers in Human Behavior, 27, pp. 1152-1161, doi:10.1016/j.chb.2010.12.009.

[11] Rogers, E.M., Diffusion of Innovations, The Free Press, New York, 1995.

[12] F.D. Davis, "Perceived Usefulness, Perceived Ease of Use, and User Acceptance of Information Technology", MIS Quarterly, 1989, 13, pp. 319-340.

[13] V. Venkatesh, and H. Bala, "Technology Acceptance Model 3 and a research agenda on interventions", Decision Sciences, 2008, 39, pp.273-315, doi:10.1111/j.15405915.2008.00192.x.

[14] W.H. DeLone and E.R. McLean, "The DeLone and McLean Model of Information Systems Success - Ten Year Update", Journal of Management Information Systems, 2003, 19, (4), pp. 9-30, doi.org/10.1080/07421222.2003.11045748.

[15] M.B. Michel-Verkerke and A.M.G.M. Hoogeboom, "Evaluation of the USE IT-Questionnaire for the Evaluation of the Adoption of Electronic Patient Records by Healthcare Professionals", Methods of Information in Medicine, 2013, 52, pp. 189-198.

[16] M.B. Michel-Verkerke and T.A.M. Spil, "The USE ITAdoption-Model to Predict and Evaluate the Adoption of Information and Communication Technology in Healthcare", Methods of Information in Medicine, 2013, 52, pp.475-483.

[17] Polit, D.F. and C.T. Beck, Essentials of Nursing Research, Wolters Kluwer | Lippincott Williams \& Wilkins, Philadelphia, 2014. 